\title{
Cognitive Profile of Zonisamide and Valproic Acid in the Treatment of Idiopathic Generalized Epilepsy: A Comparative Observational Study
}

\author{
Teresa Ramirez-García • Pedro J. Serrano-Castro • Enrique Alonso-Morillejo • \\ Patricia Perea-Justicia • Mar Iglesias-Espinosa · Tesifón Parrón-Carreño
}

Received: March 1, 2016 / Published online: April 16, 2016

(C) The Author(s) 2016. This article is published with open access at Springerlink.com

\begin{abstract}
Introduction: Calls for an alternative to valproic acid (VPA) as drug of choice for idiopathic generalized epilepsies (IGEs) have intensified since the recent International League Against Epilepsy recommendation that the drug should not be administered to women of childbearing age. Zonisamide (ZNS), a third-generation antiepileptic drug, has proven effective in generalized seizures and could be considered an alternative to VPA in this population.
\end{abstract}

Objectives: The present study was designed to examine possible differences in cognitive profile

Enhanced content To view enhanced content for this article go to www.medengine.com/Redeem/EB84F0606 AA38D5A.

T. Ramirez-García · P. J. Serrano-Castro ( $₫)$.

P. Perea-Justicia $\cdot$ M. Iglesias-Espinosa

Epilepsy Unit, Department of Neurology,

Torrecardenas Universitary Hospital, Almería, Spain

e-mail: pedro.serrano.c@gmail.com

P. J. Serrano-Castro · T. Parrón-Carreño

Department of Neuroscience and Health Sciences,

University of Almeria, Almería, Spain

E. Alonso-Morillejo

Department of Psychology, University of Almeria,

Almería, Spain between ZNS and VPA as monotherapy in patients with IGE in real-life settings.

Methods: We conducted a comparative, descriptive, observational, retrospective cohort study in two groups of patients diagnosed with IGE treated with ZNS $\geq 200 \mathrm{mg} /$ day or VPA $\geq 1000 \mathrm{mg} /$ day as stable monotherapy for at least the previous 6 months. We used specific neuropsychological tests for short- and long-term mnemonic functions, working memory, visuospatial speed, attention and processing speed, verbal fluency, executive functions, visual perception, abstraction, anxiety, depression, and apathy.

Results: We included 16 patients in the study: eight in the VPA and eight in the ZNS group. Significantly superior mean scores were obtained by the VPA group in working memory (Forward Digits test) and by the ZNS group in execution time for the Rey-Osterrieth complex figure test. No statistically significant differences were found between the groups in the remaining tests.

Conclusion: Zonisamide as monotherapy has a similar cognitive profile to that of VPA in patients with IGE. The final treatment selection setting should be individualized. ZNS 
may be a reasonable alternative to VPA in some cases in this population.

Keywords: Cognitive profile; Idiopathic generalized epilepsy; Neuropsychology; Valproic acid; Zonisamide

\section{INTRODUCTION}

The so-called third-generation antiepileptic drugs (AEDs) have not been able to modify the natural history of the disease, but they have demonstrated superior pharmacokinetic, pharmacodynamic, and adverse-effect profiles, improving the quality of life of patients with epilepsy [1, 2]. This improvement is largely attributable to the reduced cognitive or psychiatric adverse effects, which play a key role in the quality of life of patients with epilepsy [3].

Zonisamide (ZNS), a third-generation AED, was approved for clinical use in Japan in 1989, by the US Food and Drug Administration in 2000, and by the European Medicines Agency in 2005 [4]. The availability of a ZNS monotherapy regimen since 2012 in the European Union has renewed interest in this drug and its benefits, including its wide spectrum of action. Besides its accredited usefulness in the treatment of partial seizures, various studies have demonstrated its effectiveness in generalized seizures [5-7]. Zonisamide achieved a 50\% reduction in these seizures in $72.4 \%-82 \%$ of patients and freedom from seizures in $>50 \%$ of patients with different types of idiopathic generalized epilepsy (IGE) [4]. These data suggest that ZNS may be an alternative to valproic acid (VPA), which is considered the treatment of choice for this type of epilepsy in most current practice guidelines.
Few data have been published on the cognitive adverse effects of ZNS. The meta-analysis by Chadwick and Marson [8] reported that the most frequent adverse effects of ZNS treatment were ataxia, dizziness, somnolence, nervousness, and anorexia, indicating a predominance of cognitive adverse effects. However, a recent study found no differences between ZNS- and VPA-treated patients in the subjective perception of cognitive or neuropsychiatric adverse effects [9].

In light of this, the present study was designed to examine possible differences in cognitive adverse effects between ZNS and VPA as monotherapy in patients with IGE.

\section{METHODS}

\section{Objectives}

The main objective of this clinical investigation was to compare the impact on cognition of monotherapy with ZNS versus VPA in patients with IGE.

\section{Study Design}

We conducted a comparative, descriptive, observational, retrospective cohort study in two groups of patients diagnosed with IGE and treated with ZNS (ZNS group) or VPA (VPA group) as monotherapy.

\section{Patient Selection}

The authors consecutively recruited 900 patients under treatment at the Epilepsy Unit of the Torrecardenas Hospital. Inclusion criteria were age $>16$ years, a diagnosis of IGE (any variant) according to the diagnostic recommendations of the International League 
Against Epilepsy (ILAE), stable and identifiable antiepileptic treatment during the previous 6 months with VPA $\geq 1000 \mathrm{mg} /$ day or ZNS $\geq 200 \mathrm{mg} /$ day as monotherapy, capacity to provide clinical data required for the study (according to the judgment of the researcher), and written informed consent to participate in the study. Exclusion criteria were the presence of developmental delay, simultaneous treatment with psychotropic drugs, or other factors that could interfere with the neuropsychological assessment (e.g., praxis-induced seizures during the study or the presence of psychiatric comorbidity that could affect the cognitive evaluation).

\section{Sample Size Calculation}

No previous data were available for sample size estimation. Given that the objective was to compare cognitive adverse effects between two treatments, and the imposition of strict inclusion criteria, we aimed to enroll at least eight patients in each group for a preliminary comparison.

\section{Selection of Variables}

The following neuropsychological test battery was used for cognitive evaluation in all participants.

\section{Laterality Test}

Edinburgh Handedness Inventory [10] Subjects evaluate the use of one or the other hand in different basic activities of daily living using a Likert-type scale $(1=$ right very preferential; $2=$ right preferential; 3 = either hand equally; $4=$ left preferential; $5=$ left very preferential).
Short- and Long-Term Mnemonic Functions, Working Memory, and Visuospatial Speed Rey Verbal Memory (Rey Auditory Verbal Learning Test and Rey Verbal Learning Test) [11] The evaluator reads aloud a list of 15 words that patients must subsequently repeat (in any order); after subjects verbally recall all the words they remember, the same list is read out again. This procedure is repeated up to five times; this part of the test assesses short-term learning capacity and verbal memory and yields a learning curve (RAVLT1). Next, subjects undergo a distraction period of $20 \mathrm{~min}$ and are then asked to say the words they remember from the previously read list. This part evaluates long-term memory and capacity to retain verbal information (RAVLT2).

Forward and Backward Digit Span Test (WAIS-III) [12] The WAIS-III evaluates the phonological loop, concentration, and executive attention and offers a measure of immediate verbal recall and retention and the length of attention span. The examiner reads aloud a series of numbers, and the subject must repeat them, first in the same order and then in inverse order.

Rey-Osterrieth Complex Figure Test (ROCFT) [13] This test evaluates visuoperceptual construction and spatial memory through the reproduction of a geometric figure. Subjects must first produce a copy that is as identical as possible while the duration of the task is recorded. The picture is then removed and subjects are asked to reproduce it from memory. Finally, subjects undergo $20 \mathrm{~min}$ of distracting tasks and must then reproduce the figure from memory as accurately as possible, leaving out no details. The test evaluates copying capacity (ROCFT), memory (ROCFCP test and ROCFLP test), and execution time (ROCFT). 
Spatial Localization (WMS) [14] The WMS evaluates visual span, visual working memory, and concentration using a board with blocks that are tapped by the examiner in a certain order that the subject must immediately repeat (forward Corsi block test). In a second test, the subject must invert the order in which the blocks are tapped by the examiner (backward Corsi block test).

\section{Test of Attention and Processing Speed}

Trail-Making Test $A$ and $B$ [11] These are tests of visual search speed, sustained and divided attention, and cognitive flexibility. Subjects are given a sheet with a series of disordered numbers that they must join together as quickly as possible without lifting the pen from the paper (TMT-A). Subjects are then given another sheet with disordered letters and numbers that they must join together in an alternate manner and in order as quickly as possible (TMT-B).

Stroop Test [15] This test measures processing speed, selective attention, and inhibition. In the first of three parts, subjects must read a series of colors (blue, red, and green; Stroop-C test) as quickly as possible. In the second part, they must name the color of an X-shaped stimulus that is presented (Stroop-P test). In the final part, they are presented with the names of colors written in a different color to that of their name; subjects must name the color in which the word is written, inhibiting its meaning (Stroop-PC test).

\section{Verbal Fluency Test and Executive Functions}

Verbal Fluency Test (Phonetics and Semantics) [11] This test yields information on semantic memory, executive functions, and the capacity of subjects to change tasks. Subjects are asked to state in $1 \mathrm{~min}$ as many words as they can that begin with "p". Next, they are asked to say in
1 min the names of all animals they can remember, regardless of the first letter.

Zoo Map Test [16] This is included in the Behavioral Assessment of Dysexecutive Syndrome (BADS) by Alderman et al. It is a planning test in which subjects must organize a route around a zoo and visit 6 of 12 possible localizations. In the first test, the route may be planned freely with no restrictions, whereas limitations are imposed in subsequent tests.

\section{Visual Perception Test and Abstraction Capacity}

Blocks (WAIS-III) [12] This test yields information on visual perception, capacity to establish spatial relations, and visuomotor coordination. Subjects are given (identical) blocks with which they must reproduce a figure drawn on paper as quickly as possible.

Similarities (WAIS-III) This test provides information on the abstraction and reasoning capacities of participants, who must identify something that two apparently different elements share in common.

\section{Test of Anxiety, Depression, and Apathy}

Hospital Anxiety and Depression Scale (HADS) This test is a self-administered 14-item scale to evaluate subjects' mood (anxiety/depression).

Starkstein scale This test is a self-administered 14-item scale to evaluate subjects' degree of apathy.

Reference values were taken from normative data in the Spanish NEURONORMA Project [17].

We also gathered data from all participants using a standardized data collection form, including age (in years), sex, specific epilepsy syndrome diagnosis, and number of seizures during the previous 3 months. Data were included in a global study database. 


\section{Statistical Analysis}

We expressed continuous variables as means with standard deviations, medians, or range (maximum and minimum values) according to their distribution, and categorical variables as frequencies and percentages. We applied the Shapiro-Wilk or Kolmogorov-Smirnov test to examine the distribution of the variables; the Student's $t$ test or Mann-Whitney $U$ test to compare continuous variables between the groups, as appropriate; and the Chi-squared $\left(\chi^{2}\right)$ or exact Fisher tests to compare categorical variables.

\section{Compliance with Ethics Guidelines}

This article does not contain any new studies with human or animal subjects performed by any of the authors.

\section{RESULTS}

In total, 24 patients diagnosed with IGE by the Epilepsy Unit of the Torrecárdenas Hospital in Almeria met the inclusion criteria. One patient was excluded for severe depression considered to affect cognitive performance, another for praxis seizures during the cognitive examination, and a further six patients could not be contacted. Hence, the final sample included 16 patients, eight under stable treatment with VPA in monotherapy (VPA group) and eight under treatment with ZNS in monotherapy (ZNS group). Patients were assigned to these groups before the study according to clinical criteria alone.

Participants were aged between 16 and 60 years $(\dot{x}=31.74$ years, standard deviation 10.47); eight were male and eight female; $56.25 \%$ had primary schooling, $12.5 \%$ secondary schooling, and 31.25\% higher/ university education. The mean number of years of schooling was 12.88 years (standard deviation 4.09; range 8-22). Patients from both groups were seizure free in the 3 months prior to the neuropsychological exploration.

Edinburgh Handedness Inventory results showed right-hand laterality in 15 of the 16 participants and left-hand laterality in one subject.

Subjective cognitive complaints were reported by $68.75 \%$ of the sample, described as difficulties in attention (12.5\%), memory $(12.5 \%)$, or memory and attention (37.5\%), and disorientation (6.25\%).

The epilepsy diagnosis was IGE with isolated tonic-clonic seizures in nine patients, Janz juvenile myoclonic epilepsy (JME) in five, childhood absence epilepsy (CAE) in one, and juvenile absence epilepsy (JAE) in another.

As shown in Table 1, the two groups did not significantly differ in any demographic or clinical variable except that the ZNS group had more females and the VPA group had more males.

Tables 2, 3, 4, 5, and 6 exhibit the bivariate comparison of the test battery results.

Significantly superior mean scores were obtained by the VPA (vs. ZNS) group in working memory (forward digits test) and by the ZNS group in execution time for the Rey-Osterrieth complex figure test. No statistically significant differences were found between the groups in the remaining tests.

\section{DISCUSSION}

This study found no significant differences in cognitive performance between patients with IGE treated with VPA or ZNS as monotherapy, indicating that the treatment decision can be 
Table 1 Between-group comparison of demographic data

\begin{tabular}{|c|c|c|c|}
\hline Variable & VPA group & ZNS group & $P$ value \\
\hline Age (years) & 32.63 & 30.87 & NS* \\
\hline Male/female (\%) & $7 / 1(87.5 / 12.5 \%)$ & $1 / 7(12.5 / 87.5 \%)$ & $0.01^{* *}$ \\
\hline Years of schooling & 14.25 & 11.5 & NS* \\
\hline Subjective memory complaints (no/yes) & $3 / 5(37.5 / 62.5 \%)$ & $2 / 6(25 / 75 \%)$ & $\mathrm{NS}^{* *}$ \\
\hline \multirow[t]{3}{*}{ Syndrome diagnosis } & 4 TCGS & 5 TCGS & $\mathrm{NS}^{* *}$ \\
\hline & $3 \mathrm{JME}$ & $2 \mathrm{JME}$ & \\
\hline & $1 \mathrm{CAE}$ & $1 \mathrm{JAE}$ & \\
\hline Mean number of generalized seizures during previous 3 months & 0 & 0 & $N S^{* *}$ \\
\hline
\end{tabular}

individualized according to effectiveness criteria or other types of adverse effect.

Although VPA is the AED of choice in most clinical practice guidelines for IGE, it is associated with teratogenic and adverse esthetic effects (obesity, hirsutism, alopecia) that have an especially negative impact in young women [18, 19]. An increased risk of autism has been reported in the children of epileptic mothers exposed to VPA during pregnancy [20]. Calls for an alternative to VPA [21] have intensified following the recent ILAE recommendation that this drug not be administered to girls or women of childbearing age [22]. ZNS may be a good alternative option in this patient population given its wide action spectrum, including different types of generalized seizures, and its favorable profile of esthetic adverse effects [4]. Nevertheless, perhaps due to certain similarities with topiramate (TPM), ZNS has been considered to have a worse cognitive profile than VPA, despite the absence of studies directly comparing these AEDs. This has contributed to limited administration in patients with IGE because of the important impact of adverse cognitive effects on quality of life [23].

A review of the efficacy and safety of ZNS in combined therapy for focal epilepsy demonstrated a good long-term cognitive tolerability profile [24], whereas a study of patients treated with ZNS, TPM, or levetiracetam for alcohol abuse disorder observed superior cognitive performance in ZNS-treated versus TPM-treated patients, mainly in relation to processing speed [25]. However, a recent prospective study in 14 patients with different types of epilepsy found that ZNS treatment impaired performance in memory, attention (TMT A and B), and verbal fluency tests in a dose-dependent manner and that these effects were sustained over time [26]. Hence, published research on the cognitive impact of ZNS is scarce and results controversial.

Although VPA has been commercially available for many years and is widely used in epilepsy treatment, few data have been published on its possible adverse cognitive effects. Meador et al. [27] compared the side effects of phenobarbital (PB), phenytoin (PHT), 
Table 2 Between-group comparison of results in mnemonic tests and working memory

\begin{tabular}{llll}
\hline Variable & VPA group & ZNS group & $\boldsymbol{P}$ \\
\hline RAVLT1 & $5.88(1.55)$ & $6.63(1.59)$ & $\mathrm{NS}$ \\
RAVLT2 & $11.88(1.96)$ & $12.13(2.74)$ & $\mathrm{NS}$ \\
RVLT & $10.25(3.06)$ & $10.50(2.97)$ & $\mathrm{NS}$ \\
FD & $8.63(3.33)$ & $5.13(2.85)$ & $0.04^{*}$ \\
BD & $9.25(1.91)$ & $7.50(0.75)$ & $\mathrm{NS}$ \\
ROCF & $12.25(3.24)$ & $9.50(3.66)$ & $\mathrm{NS}$ \\
ROCFT & $8(2.62)$ & $13.25(5.42)$ & $0.05^{*}$ \\
ROCFST & $9.38(3.02)$ & $10.75(1.28)$ & $\mathrm{NS}$ \\
ROCFLT & $8.50(3.81)$ & $11.13(2.03)$ & $\mathrm{NS}$ \\
CORSI-F & $9.13(4.55)$ & $6.63(2.38)$ & $\mathrm{NS}$ \\
CORSI-B & $9.63(3.20)$ & $7.88(2.95)$ & $\mathrm{NS}$ \\
\hline
\end{tabular}

Data are presented as mean (standard deviation)

$B D$ backward digits, CORSI-B backward Corsi block test, CORSI-F forward Corsi block test, FD forward digits, NS non-significant, RAVLT Rey Auditory Verbal Learning Test, ROCF Rey-Osterrieth complex figure, ROCFLT long-term memory of Rey-Osterrieth complex figure, ROCFST short-term memory of Rey-Osterrieth complex figure, ROCFT execution time of the direct copy of Rey-Osterrieth complex figure, RVLT Rey Verbal Learning Test, $V P A$ valproic acid, $Z N S$ zonisamide

* Mann-Whitney $U$ test

Table 3 Between-group comparison of attention and processing speed test results

\begin{tabular}{llll}
\hline Variable & VPA group & ZNS group & $\boldsymbol{P}$ value \\
\hline TMT-A & $8.13(3.39)$ & $6(4.14)$ & NS \\
TMT-B & $6.38(3.58)$ & $6(3.62)$ & NS \\
Stroop-C & $9.13(2.64)$ & $7.38(3.16)$ & NS \\
Stroop-P & $6.75(3.49)$ & $7.38(4.07)$ & NS \\
Stroop-PC & $8.13(4.01)$ & $7.38(3.89)$ & NS \\
\hline
\end{tabular}

Data are presented as mean (standard deviation) NS non-significant, TMT Trail Making Test, VPA valproic acid, $Z N S$ zonisamide
Table 4 Between-group comparison of verbal fluency and executive function test results

\begin{tabular}{llll}
\hline Variable & VPA group & ZNS group & $\boldsymbol{P}$ value \\
\hline Animals & $5(2.77)$ & $5(1.77)$ & NS \\
P Word test & $6.88(3.31)$ & $6.38(2.50)$ & NS \\
Zoo Map test & $2.50(0.53)$ & $2.75(0.46)$ & NS \\
\hline
\end{tabular}

Data are presented as mean (standard deviation)

$N S$ non-significant, $V P A$ valproic acid, $Z N S$ zonisamide

Table 5 Between-group comparison of results in visual perception and abstraction capacity tests

\begin{tabular}{llll}
\hline Variable & VPA group & ZNS group & P value \\
\hline $\begin{array}{c}\text { Blocks } \\
\text { WAIS-III }\end{array}$ & $8(1.92)$ & $6.63(2.38)$ & NS \\
$\begin{array}{c}\text { Similarities } \\
\text { WAIS-III }\end{array}$ & $9.13(3.13)$ & $10.75(3.49)$ & NS \\
\hline
\end{tabular}

Data are presented as mean (standard deviation)

$N S$ non-significant, $V P A$ valproic acid, $Z N S$ zonisamide

Table 6 Between-group comparison of results in anxiety, depression, and apathy tests

\begin{tabular}{llll}
\hline Variable & VPA group & ZNS group & $\boldsymbol{P}$ value \\
\hline HADS anxiety & $2(4.50)$ & $1.38(1.40)$ & NS \\
HADS depression & $0.38(1.06)$ & $0.38(1.06)$ & NS \\
Starkstein scale & $1.75(3.28)$ & $1.25(1.39)$ & NS \\
\hline
\end{tabular}

Data are presented as mean (standard deviation)

HADS Hospital Anxiety and Depression Scale, NS non-significant, $V P A$ valproic acid, $Z N S$ zonisamide

and VPA and only observed a worse cognitive performance in the $\mathrm{PB}$ group, with no differences between the PHT and VPA groups. The same group found that cognitive adverse effects were slightly worse with TPM than with VPA [28], and TPM is known to be associated with a poor neuropsychological profile [29]. 
To the best of our knowledge, our study is the first to directly compare cognitive function between IGE patients treated with VPA or ZNS in real-life settings, applying tests of cognitive performance in mnemonic capacity (including working memory, verbal material, and visual material memory), verbal fluency, executive functions, visual perception, abstraction capacity, visuospatial praxis, attention, and processing speed, as well as tests evaluating depression, anxiety, and apathy.

The iatrogenic cognitive adverse effect profile of AEDs conventionally corresponds to a reduction in attention level and processing speed, with a possible impact on memory and verbal fluency, while other cortical functions are relatively unaffected [30]. In the present study, no significant differences were found between VPA and ZNS monotherapy in most variables related to iatrogenic cognitive dysfunction, indicating that cognitive performance is no more greatly impaired by ZNS than by VPA. For this reason, ZNS may be a reasonable alternative to VPA in patients with IGE. This message is reinforced by the observation that ZNS showed good efficacy and tolerability in the treatment of myoclonic seizures in patients with progressive myoclonic epilepsy [31].

In terms of the visuospatial praxis, both groups showed a similar execution capacity in the ROCFT, but the ZNS group completed it more quickly. These results are interpreted as indicating a superior performance by the ZNS group in complex praxis, i.e., in purely cortical domains.

The VPA group achieved better results (vs. the ZNS group) in the Forward Digit test, which evaluates sustained attention and concentration capacity, whereas no between-group differences were found in the Backward Digit test, which is more closely related to working memory, attention control, and executive attention. These findings may indicate a slightly worse selective attention or concentration in ZNS-treated patients, with no differences between groups in executive attention. However, no significant between-group differences were found in other attention tests (e.g., Trail-Making or Stroop Tests).

The only significant difference in baseline clinical and demographic variables (see Table 1) was in sex. The higher proportion of females in the ZNS group ( $87.5 \%$ vs. $12.5 \%$ ) is attributable to the ILAE recommendations that VPA should be avoided in young women. Nevertheless, this cannot be considered a study bias, because sex is not expected to influence cognitive performance in the studied tasks.

The main limitations of this study are the small sample size, caused by our strict inclusion criteria, and the absence of a baseline cognitive assessment, which would be ideal for the goal that we pursue. However, this is not ethically feasible in clinical practice as it would mean a delay in the start of treatment. On the other hand, it is possible that our study excluded patients with severe cognitive side effects that have not reach 6 months of treatment. However, the analysis of the published series shows no significant difference in retention rates between the two molecules [32, 33].

As this is the first study to directly compare the cognitive profile of the two monotherapies in real-life settings, other studies may be needed to confirm and refine our results.

\section{CONCLUSIONS}

Zonisamide as monotherapy has a similar cognitive profile to that of VPA in patients with IGE. The final treatment selection setting should be individualized. In terms of cognitive 
performance, there appears to be no reason to select one drug over the other, and the decision should be based on individual effectiveness, comorbidities, and somatic or esthetic adverse effects.

\section{ACKNOWLEDGMENTS}

No funding or sponsorship was received for this study or publication of this article. All named authors meet the International Committee of Medical Journal Editors (ICMJE) criteria for authorship for this manuscript, take responsibility for the integrity of the work as a whole, and give final approval for the version to be published.

Disclosures. Pedro J. Serrano-Castro has been an invited speaker for, and participated in advisory boards organized by, Shire, Eisai Ltd, Bial, Esteve, and UCB-Pharma. Teresa Ramirez-García, Enrique Alonso-Morillejo, Patricia Perea-Justicia, Mar Iglesias-Espinosa, and Tesifón Parrón-Carreño have no relevant disclosures.

Compliance with Ethics Guidelines. This article does not contain any new studies with human or animal subjects performed by any of the authors.

Open Access. This article is distributed under the terms of the Creative Commons Attribution-NonCommercial 4.0 International License (http://creativecommons.org/licenses/ by-nc/4.0/), which permits any noncommercial use, distribution, and reproduction in any medium, provided you give appropriate credit to the original author(s) and the source, provide a link to the Creative Commons license, and indicate if changes were made.

\section{REFERENCES}

1. Sander JW. The use of antiepileptic drugs-principles and practice. Epilepsia. 2004;45 Suppl 6(12):28-34.

2. Löscher W, Schmidt D. Modern antiepileptic drug development has failed to deliver: ways out of the current dilemma. Epilepsia. 2011;52(4):657-78.

3. Berto P. Quality of life in patients with epilepsy and impact of treatments. Pharmacoeconomics. 2002;20(15):1039-59.

4. Villanueva V, Serrano-castro PJ. Zonisamida en el tratamiento de la epilepsia: revisión de la bibliografía desde la terapia añadida a la monoterapia. Rev Neurol. 2013;56(8):429-38.

5. Kothare SV, Valencia I, Khurana DS, Hardison H, Melvin JJ, Legido A. Efficacy and tolerability of zonisamide in juvenile myoclonic epilepsy. Epileptic Disord. 2004;6:267-70.

6. Marinas A, Villanueva V, Giráldez BG, Molins A, Salas-Puig J, Serratosa JM. Efficacy and tolerability of zonisamide in idiopathic generalized epilepsy. Epileptic Disord. 2009;11:61-6.

7. Wilfong A, Schultz R. Zonisamide for absence seizures. Epilepsy Res. 2005;64:31-4.

8. Chadwick DW, Marson AG. Tratamiento complementario con zonisamida para la epilepsia parcial resistente a fármacos. Biblioteca Cochrane Plus 2008; no. 4. Oxford: Update Software; 2008.

9. Chen B, Detyniecki K, Hirsch LJ, Moeller J, Javed A, Kato K, Legge A, Buchsbaum R, Choi H. Cross-sensitivity of patient-perceived adverse cognitive effects with antiepileptic drug use. Epilepsy Behav. 2015;46:151-7.

10. Oldfield RC. The assessment and analysis of handedness: the Edinburgh inventory. Neuropsychologia. 1971;9(1):97-113.

11. Spreen O, Strauss E. A compendium of neuropsychological test: administration, norms and commentary. New York: Oxford UniversityPress; 1991.

12. Wechsler D. Escala de Inteligencia de Wechsler para adultos-III. Manuel de aplicación y corrección. $3^{\circ}$ Edición. Madrid: TEA Ediciones, S.A; 2001.

13. Rey A. Test de copia y de reproducción de memoria de figuras geométricas complejas. Madrid: TEA Ediciones, S.A; 2003. 
14. Wechsler D. WMS-III. Escala de memoria de Wechsler-III. Manual de aplicación y puntuación. Madrid: TEA Ediciones, S.A; 2004.

15. Golden CJ. Stroop. Test de colores y palabras. Madrid: TEA Ediciones, S.A; 2001.

16. Wilson BA, Emslie H, Evans JJ, Burgess PW. Behavioral Assessment of the Dysexecutive Syndrome (BADS). Oxford: Pearson Education Limited; 1996.

17. Peña-Casanova J, Blesa R, Aguilar $M$, Gramunt-Fombuena N, Gómez-Ansón B, Oliva R, Molinuevo JL, Robles A, Barquero MS, Antúnez C, Martínez-Parra C, Frank-García A, Fernández M, Alfonso V, Sol JM, NEURONORMA Study Team. Spanish Multicenter Normative Studies (NEURONORMA Project): methods and sample characteristics. Arch Clin Neuropsychol. 2009; 24(4):307-19.

18. Tomson T, Battino D. Teratogenic effects of antiepileptic drugs. Lancet Neurol. 2012;11(9): 803-13.

19. Luef G. Female issues in epilepsy: a critical review. Epilepsy Behav. 2009;15(1):78-82.

20. Christensen J, Grønborg TK, Sørensen MJ, Schendel D, Parner ET, Pedersen LH, Vestergaard M. Prenatal valproate exposure and risk of autism spectrum disorders and childhood autism. JAMA. 2013; 309(16):1696-703.

21. Arzimanoglou A, Ryvlin P, Perucca E. When the past challenges the present: are older antiepileptic drugs still the best choice in childhood absence epilepsy? Lancet Neurol. 2010;9(5):457-9.

22. Tomson T, Marson A, Boon P, Canevini MP, Covanis A, Gaily E, Kälviäinen R, Trinka E. Valproate in the treatment of epilepsy in girls and women of childbearing potential. Epilepsia. 2015; 56(7):1006-19.

23. Mula M, Cock HR. More tan seizures: improving the lives of people with refractory epilepsy. Eur J Neurol. 2015;22(1):24-30.

24. Schulze-Bonhage A. The safety and long-term efficacy of zonisamide as adjunctive therapy for focal epilepsy. Expert Rev Neurother. 2015;15(8): 857-65.

25. Knapp CM, Ciraulo DA, Sarid-Segal O, Richardson MA, Devine E, Streeter CC, et al. Zonisamide, topiramate, and levetiracetam. J Clin Psychopharmacol. 2015; 35(1):34-42.

26. Park SP, Hwang YH, Lee HW, Suh CK, Kwon SH, Lee BI. Long term cognitive and mood effects of zonisamide monotherapy in epilepsy patients. Epilepsy Behav. 2008;12(1):102-8.

27. Meador KJ, Loring DW, Moore EE, Thompson WO, Nichols ME, Oberzan RE, Durkin MW, Gallagher BB, King DW. Comparative cognitive effects of phenobarbital, phenytoin, and valproate in healthyadults. Neurology. 1995;45(8):1494-9.

28. Meador KJ, Loring DW, Hulihan JF, Kamin M, Karim R, CAPSS-027 StudyGroup. Differential cognitive and behavioraleffects of topiramate and valproate. Neurology. 2003;60(9):1483-8.

29. Javed A, Cohen B, Detyniecki K, Hirsch LJ, Legge A, Chen B, Bazil C, Kato K, Buchsbaum R, Choi H. Rates and predictors of patient-reported cognitive side effects of antiepileptic drugs: an extended follow-up. Seizure. 2015;29:34-40.

30. Meador KJ, Gilliam FG, Kanner AM, Pellock JM. Cognitive and behavioral effects of antiepileptic drugs. Epilepsy Behav. 2001;2(4):SS1-17.

31. Italiano D, Pezzella M, Coppola A, Magaudda A, Ferlazzo E, Bramanti P, Striano S, Zara F, Striano P. A pilot open-label trial of zonisamide in Unverricht-Lundborg disease. Mov Disord. 2011; 26(2):341-3.

32. Kim DW, Choi K, Moon HS, Oh J. Long-term retention rate of zonisamide in patients with epilepsy: an observational study. Clin Neuropharmacol. 2014; 37(5):133-5.

33. Jedrzejczak J, Kuncíková M, Magureanu S, VIPe Study Group. An observational study of first-line valproate monotherapy in focal epilepsy. Eur J Neurol. 2008;15(1):66-72. 